\title{
Factors Affecting Consumer Attitudes Toward Chain Super Store Brands in Bangladesh
}

\author{
Shamima Akter" \\ Assistant Professor, Department of Business Administration, City University, Dhaka, Bangladesh
}

Md. Zahidur Rahman

Lecturer Department of Business Administration, City University, Dhaka, Bangladesh

\begin{abstract}
The current study analyzes the impact of various communicational avenues (Controlled communication, uncontrolled communication) and brand name over brand attitude in the context of Retail Industry in Bangladesh. The nature of the study will be co relational, and the researcher will conduct questionnaire survey for further analyses to examine the relationships among research variables. The researcher will use statistical techniques such as mean, correlation, regression, and standard deviation in this study. The results of the correlation analyses will provide full support to all the research hypotheses; however regression analyses will provide partial support to the research hypotheses.
\end{abstract}

Keywords: Brand name; Brand attitude; Controlled communication; Uncontrolled communication.

\section{(9) (i) CC BY: Creative Commons Attribution License 4.0}

\section{Introduction}

With the consistent development and changes in the global economy, retail industry culture plays a vital role in our society as well as economy. The lifestyle, preference and demands of consumers are changing rapidly. The world is becoming so fast that the customers don't have much time to go for shopping in different markets at a time. They would rather go to a market or a shop where they can buy the all types of products at once from the same place. Thus, the retail concept came to make all the product available under one roof for the customer. Shopping all essential goods from a retail outlet is very common in developed country. So there are many established super shop chain exits in those countries. Wal-Mart, Kmart, Tesco are some examples of retail outlets in chain and India that operate businesses all over the world with a great success. Super shop concept established in Bangladesh not too far ago. Bangladesh is developing very fast for the last few years. Consumers' behaviors are also changing at the same rate. Consumers are becoming more habitual to follow developed countries shopping trends. Siddiqui et al. (2006) found that With the enormous growth of urban population in Bangladesh, the retail market of the country is modernizing, particularly in Dhaka, the capital city. With the introduction of retail outlets 2000s, the retail not only just developing, but also moving ahead very fast with different dimensions.

A number of super shop have been are established in the last few years. Some notable names are AGORA, SHOPNO, MEENA BAZAR, NONDON etc. All of them are mainly Dhaka based super chain stores, but some of them are also available in other cities too. AGORA is the first retail super shop chain that introduced in 2001 and it is the largest super shop in Dhaka city. As there are a number of retail outlets available to the customers and the services, product variety, geographic coverage and competiveness are increasing in Dhaka, customers are getting more option to choice a super shop. So there is an importance of studying the related factors (i.e. controlled communication, uncontrolled communication, brand name) that influence a customer choosing a particular retail shop in Dhaka.

\subsection{Purpose of the Study}

Shopping from retail outlet is becoming very popular in Dhaka city day by day. Customers are becoming more interested to go to a retail outlet for all kinds of products rather to go to different small grocery shops around. The number of retail outlet and its branches are rising rapidly. So, customers have option to choose a retail outlet. To capture new market and maintain a sustainable growth of market share as well as sales, retail industry are trying to develop positive brand attitude among customers through controlled communication such as promotion, advertisement and uncontrolled communication such as non-paid publicity, word of mouth competitive price. The study will examines the effect of controlled communication, uncontrolled communication and brand name on brand attitude that influence a customer to choose a particular retail outlet in the context of Bangladesh.

\subsection{Limitation of the Study}

There are some constrains or limitations in this study. The survey was conducted only Dhaka district thus the sample size was small to consider the whole scenario. Limitation of time was one of the major drawbacks. Sometimes participants were unwilling to answer and it was difficult to convince them to answer all the questions. 


\section{Literature Review}

\subsection{Controlled Communication}

Controlled communication implies the messages that the marketer delivers to the consumers. The marketer has full control on the message content, when and how the message will be delivered and to whom it will be delivered. Advertising and other promotional activities undertaken fall under this category. Traditional controlled communication avenues like promotion, publicity and brand name have also been considered as controlled communications, and it is argued that controlled communications can influence consumer's response to the brand (Grace and O'Cass, 2005). In terms of services, controlled communications such as advertising are argued to be an important tool used to communicate the service. For example, service advertisements adopting a rational or informational approach have been shown to reduce uncertainty and increase the likelihood of future purchase intentions (Stafford and Day, 1995) While the objective of any controlled communications, such as advertising, is to communicate information to consumers, we know that it is the degree to which the information is meaningful to consumers that is important. Therefore, the more favorable the consumer's feelings and attitudes are towards the communications; the more likely it is that the communications will be effective in transferring relevant meaning about the brand.

\subsection{Uncontrolled Communication}

Uncontrolled communication primarily consists of word-of mouth (WOM) behavior and unpaid publicity. Largely derived from personal sources, WOM communications are an important source of information for service consumers prior to patronage. For example, it has been shown that WOM communications significantly affect consumer purchasing behavior (Mangold et al., 1999) and influence both short-and long-term judgments (Bone, 1995). According to Grace and O'Cass (2005) uncontrolled communication found to had less effect on customer attitude as well as re-purchase intention. Uncontrolled communications such as WOM and non paid publicity are argued as having stronger influence on brand attitude (Swanson and Kelley, 2001). Another form of uncontrolled communication comes in the form of non paid public relations. Often referred to as "publicity", this form of message communication is similar to WOM in the sense that negative publicity is said to have a greater influence on consumer response than positive publicity. In a similar vein to WOM, publicity is also viewed as a credible source of information that is more influential than marketer-driven communications (Ahluwalia et al., 2000). Furthermore, Hauss (1993) advocates that, regarding the attitudes of people towards political parties, there is not doubt that good and bad media coverage has a profound effect.

\subsection{Brand Name}

A good Brand name being argued to create high levels of brand awareness, stimulate strong consumer preference and contribute to the success of the product (Chan and Huang, 1997). In fact, many have noted the importance of brand names in consumer evaluations of brands, in that, brand names assist the consumer in recalling brand benefits (Janiszewski and van Osselaer, 2000), in making product inferences and evaluations (Zinkhan and Prenshaw, 1994). Degeratu et al. (2000), note that the brand name is weighted as even more important when there is lack of available information, as the brand name becomes a surrogate for attribute information that is missing. Grace and O'Cass (2005) suggested that brand name should be acknowledged for its contribution in communicating the brand rather than simply being judged as an element of a brand. This being the case, the brand name should be recognized for the more proactive role it plays in communicating the brand, rather than simply being viewed as a component of the brand. For example, the consumers' personal experiences and what is known of others' experiences with the brand will result in information and meaning being attached to the brand name in memory.

\subsection{Brand Attitude}

Defined as "the consumer's overall evaluation of a brand whether good or bad" (Low and Lamb, 2000), brand attitudes encapsulate the meaning that consumers attach to brands, which in turn effects their purchasing behavior (Low and Lamb, 2000). Therefore, positive brand attitudes are vital to the long-term success and sustainability of brands (Hoek et al., 2000). Relationship between controlled communication and brand attitude In terms of controlled communications, advertising has long been proclaimed as an important avenue by which marketers can make their offerings to customers tangible. However, in many cases, service consumers rely heavily on information from commercial sources (advertising communications) in order to make their brand choices. In terms of controlled communication, advertising has been consistently found to play an important role in creating positive brand attitudes (Kempf and Smith, 1998). Effective brand communications are however important for creating and maintaining positive brand attitudes (Grace and O'Cass, 2005).

\section{Proposed Conceptual Framework}

To give direction to the investigation, the researcher developed a conceptual framework based on insights gain from the literature review. While a number of theories and issues pertinent to the study were discussed in the literature review, the following concepts were chosen as the basis of the analysis of the research problem. These were uncontrolled communication, controlled communication, brand name and brand attitude. According to (Ticehurst and Veal, 2000), "a conceptual framework indicates how researcher views the concepts involved in a study - especially the relationships between concepts. 
Figure-1. Conceptual Framework of Research Variables and their Relationships

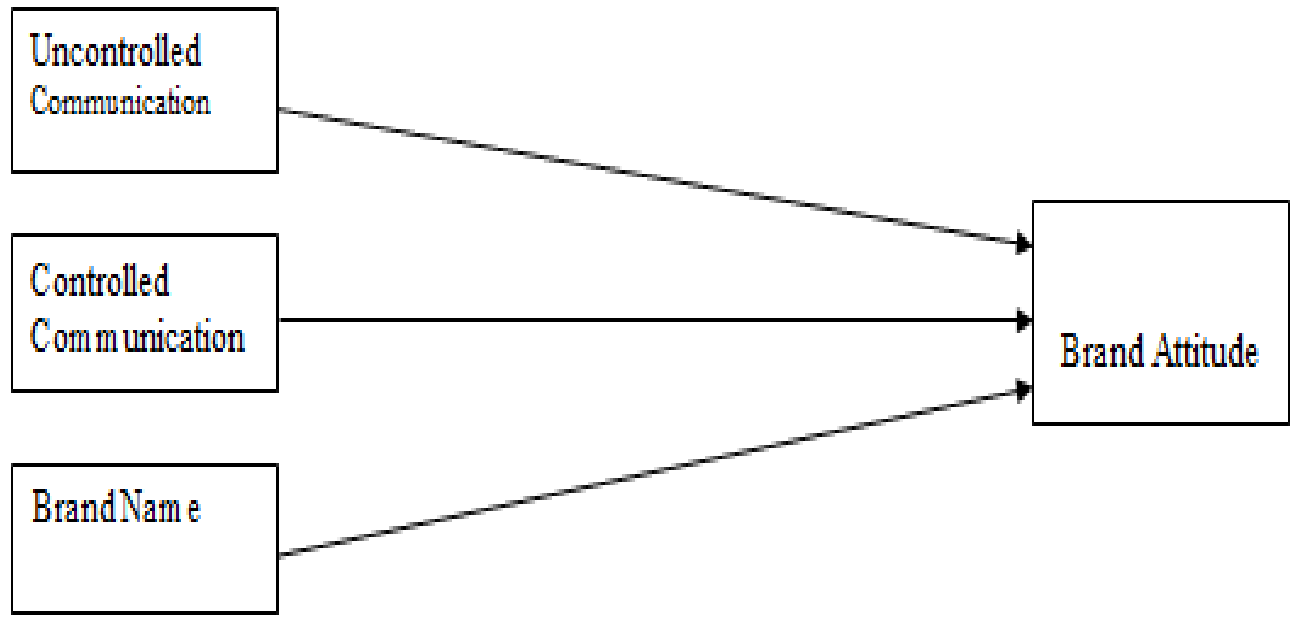

In addition, the development of the conceptual framework, specific research questions and hypothesis are portrayed below.

\subsection{Research Questions and Hypotheses}

\subsection{Research Questions}

RQ 1 Is there any significant relationship between uncontrolled communication and brand attitude in the context of Retail industry Sector in Bangladesh?

RQ 2 Is there any significant relationship between controlled communication and brand attitude in the context of Retail industry Sector in Bangladesh?

RQ 3 Is there any significant relationship between brand name and attitude in the context of Retail industry Sector in Bangladesh?

\subsection{Hypotheses}

H1. There is a significant relationship between uncontrolled communication and brand attitude in the context of Retail industry Sector in Bangladesh.

H2. There is a significant relationship between controlled communication and brand attitude in the context of Retail industry Sector in Bangladesh.

H3. There is a significant relationship between brand name and brand attitude in the context of Retail industry Sector in Bangladesh.

\section{Methodology}

\subsection{Research Design}

The study is exploratory study. An index is built for each of the independent variables and dependent variable asking consumers different set of questions using 5 point likart Scale. Then the score given on each questions were summed up to measure the score of each variable, These score are used in data analysis. Data analysis involved descriptive analysis, correlation and step-wise regression.

\subsection{Sampling Method}

The populations of this research are the consumer of retail chain stores in Dhaka city. The sample size is 104 . The sampling technique used is non-probability convenience sampling technique. Data was gathered through questionnaire which was distributed to 140 consumer of the most popular retail stores like AGORA,SHAWAPNO,MEENA BAZAR and PRINCE. Hundred and two 104 questionnaires were found correct for data analysis. Therefore, researcher uses 102 questionnaires for data analysis.

\subsection{Survey Instrument}

Since previous researcher also used questionnaire to complete the survey. A structured question is used in this research to collect data from the respondents. The questionnaires divided in four sections. The sections are Controlled communications, Uncontrolled communication, Brand name and Brand attitude. There are 25 questions. $1-6$ are for Controlled communications, 7 - 16 are for Uncontrolled communication, 17-21 are for Brand name and $22-25$ are for Brand attitude. All question has used 5-point likert scale regarding from 1 (strongly disagree) to 5 (strongly agree).

\subsection{Data Collection Procedure}

The present research is addressing unique characteristics so availability of secondary data is impossible. Therefore data was collected through questionnaire. 


\subsection{Data Analysis}

After collecting the data, the researcher used Pearson's co-relational matrix for the variables are prepare and the researchers look for significant correlations. The researcher used descriptive, correlation, and step-wise regression to test the strength of association between the studied variables. The Statistical Package for Social Science (SPSS) version 22 software is employed to analyze the data collected from the actual survey.

\section{Research Findings}

\subsection{Reliability and Descriptive statistics of the Instruments}

The reliability coefficients, means and standard deviations of all the constructs in the current study are displayed in Table1. The coefficient alphas for the different constructs were computed using the reliability procedure in SPSS (version 12.0). Nunnally (1978) suggested that for early stages of any research the reliability of .50-.60 is sufficient. The reliabilities of all the constructs in this study found to be above the standard set by Nunnally (1978).

Table-1. Descriptive statistics, and Reliability Coefficient of uncontrolled communication, controlled communication, brand name, and brand attitude

\begin{tabular}{l|l|l|l|l}
\hline Scale & No. of Items & Alpha & Mean & SD \\
\hline Controlled communication & 6 & 0.66 & 4.17 & 0.47 \\
\hline Uncontrolled communication & 10 & 0.82 & 4.05 & 0.57 \\
\hline Brand name & 5 & 0.76 & 4.14 & 0.60 \\
\hline Brand attitude & 4 & 0.74 & 4.19 & 0.61 \\
\hline Note: $\mathrm{n}=10$ & \multicolumn{3}{|r}{}
\end{tabular}

Mean scores have been computed by equally weighting the mean scores of all items. On a five point scale mean score for controlled communication is $4.17(\underline{\mathrm{sd}}=.47)$. The mean score for uncontrolled communication is $4.05(\underline{\mathrm{sd}}=$ $.57)$. The mean score for brand name is $4.14(\underline{\mathrm{sd}}=.60)$. The mean score for brand attitude is $4.19(\underline{\mathrm{sd}}=.61)$. It indicates that people's attitude towards retail chain store brand is favorably high.

\subsection{Correlation Analysis}

A correlation analysis was conducted on all the variables to explore the relationships between the measured variables.

Table-2. Correlation Matrix for uncontrolled communication, controlled communication, brand name, and brand attitude
\begin{tabular}{l|l|l|l|l}
\hline Scale & Con_com & Uncom_com & Bra_name & Bra_att \\
\hline Controlled communication & 1 & $.753^{* *}$ & $.571^{* *}$ & $.656^{* *}$ \\
\hline Uncontrolled communication & & 1 & $.730^{* *}$ & $.734^{* *}$ \\
\hline Brand name & & & 1 & $.714^{* *}$ \\
\hline Brand attitude & & & & 1 \\
\hline Note: ${ }^{*}$ p $<.01$ &
\end{tabular}

The result of correlation analysis for all the variables is shown in Table 2. It examines the correlation among uncontrolled communication, controlled communication, brand name, and brand attitude. The variables significantly correlated with brand attitude are controlled communication $(\mathrm{r}=.65, \mathrm{p}<.01)$, uncontrolled communication $(\mathrm{r}=.73$, $\mathrm{p}<.01)$, and brand name $(\mathrm{r}=.71, \mathrm{p}<.01)$.

\subsection{Stepwise Regression Analysis}

Stepwise regression was conducted to asses the relationship between variables. Hanushek and Jackson (1977) suggested that stepwise regression is a useful procedure in determining most significantly related variables in explaining the behavior in question and this procedure not only gives an indication of how comprehensive the effect of the independent variable is, but also details which aspects of a grossly defined variable have been differentially affected.

Table-3. Stepwise Regression on Brand attitude

\begin{tabular}{l|c|l|l|l|l}
\hline Scale & $\mathbf{B}$ & $\mathbf{S E B}$ & $\boldsymbol{\beta}$ & $\mathbf{R}^{\mathbf{2}}$ & $\Delta \mathbf{R}^{\mathbf{2}}$ \\
\hline Step 1 & & & & .539 & \\
\hline Uncon_com & .783 & .072 & $.734^{* * *}$ & & \\
\hline Step-2 & & & & .607 & .068 \\
\hline Uncon_com & .486 & .097 & $.456^{* * *}$ & & \\
\hline Brand name & .385 & .092 & $.382^{* * *}$ & & \\
\hline Step-3 & & & & .628 & .021 \\
\hline Uncon_com & .318 & .119 & $.298^{* *}$ & & \\
\hline Brand name & .375 & .090 & $.371^{* * *}$ & & \\
\hline Con_com & .282 & .119 & $.219^{*}$ & & \\
\hline *p $<.05, * * \mathrm{p}<.01, * * * \mathrm{p}<.001$ & & & &
\end{tabular}


Table 3 depicts that in case of retail chain store uncontrolled communication ( $p<.01)$, controlled communication $(\mathrm{p}<.05)$, and brand name $(\mathrm{p}<.001)$ has been found to be statistically significantly related with brand attitude. These results provided full support for the research hypothesis. These three predictor variables together explained $63 \%$ of the variance in brand attitude. Uncontrolled communication, brand name and controlled communication explained about $54 \%, 7 \%$ and $2 \%$ of the variance in brand attitude respectively.

\section{Recommendation}

Analysis has shown that all the hypotheses have been proved correct. The study variables controlled, uncontrolled communication and brand name are significantly related to brand attitude. The three independent variables clearly influence the dependent variable brand attitude i.e. they all contribute to attitude that consumers have regarding retail chain store in Bangladesh.

The study has shown that controlled communication influences the attitude or perception that company representatives from regarding a brand. Therefore, advertising and promotions should be used to encourage positive behavioral intentions by making offers (e.g. special price, deals, off-peak promotions), implying scarcity, or encouraging urgency of response. Promotions such as "User get User" ( referral marketing), and other such promotions have proved successful so they should come up with more innovative and creative but relevant communication messages to the enhance the attitude of both users and non users (prospective users) towards the particular brand, and retail chain stores can play a vital role in this factor.

The study has shown that uncontrolled communication elements such as WOM and non-paid publicity largely influences brand attitude. So it is imperative that the people at respective organization should work very hard to induce such behavior from the subscribers. The best way to do this is by satisfying them since a satisfied customer would engage in positive WOM behavior and thus significantly influence both current and prospective customers in forming a positive attitude toward retail chain stores. The publicity generated from sponsoring events and participating in socially responsible activities would greatly help in reinforcing and enhancing the attitude of people about retail chain stores. The brand name of retail chain stores are highly significant since company representatives often perceive it as signifying aggressive growth and offering value for money, this has huge implications in formulating people's attitudes and perceptions about the brand. The study supports this theory. In terms of the brand name, this should be utilized to reduce behavioral risk by reinforcing proven reliability and consistency of performance associated with retail chain stores. So retail chain stores in Bangladesh should strive to further enhance their name by enhancing brand image.

\section{Conclusion}

The study has shown that uncontrolled communication, controlled communication and brand name significantly influence brand attitude of consumers towards a brand. So we can see that in order for retail chain stores to induce a positive attitude of people towards the brand they should pay careful attention to elements such as their advertising strategy and other promotional activities, encourage positive WOM behavior, strive to get favorable non-paid publicity and also work to further enhance its name.

\section{References}

Ahluwalia, R., Burnkrant, R. E. and Unnave, H. R. (2000). Consumer response to negative publicity, the moderating role of commitment. Journal of Marketing Research, 37(2): 203-14.

Bone, P. F. (1995). Word-of-mouth effects on short-term and long-term product judgments. Journal of Business Research, 32(3): 213-23.

Chan, A. K. K. and Huang, Y. Y. (1997). Brand naming in China, a linguistic approach. Marketing Intelligence \& Planning, 15(5): 227-34.

Degeratu, A. M., Rangaswamy, A. and Wu, J. (2000). Consumer choice behaviour in online and traditional supermarkets: the effects of brand name, price and other search attributes. International Journal of Research in Marketing, 17(1): 55-78.

Grace, D. and O'Cass, A. (2005). Examining the effects of service brand communications on brand evaluation. Journal of Product and Brand Management, 14(2): 106-16.

Hanushek, E. A. and Jackson, J. E. (1977). Statistical methods for social scientists. Academic Press Inc: NY.

Hauss, D. (1993). Measuring the impact of public relations. The Public Relations Journal, 49(2): 14-20.

Hoek, J., Dunnett, J., Wright, M. and Gendall, P. (2000). Descriptive and evaluative attributes, what relevance to marketers? Journal of Product \& Brand Management, 9(6): 415-35.

Janiszewski, C. and van Osselaer, S. M. J. (2000). A connectionist model of brand-quality associations. Journal of Marketing Research, 37(3): 331-50.

Kempf, D. S. and Smith, R. E. (1998). Consumer processing of product trial and the influence of prior advertising, a structural modelling approach. Journal of Marketing Research, 25: 325-38.

Low, G. S. and Lamb, C. W. J. (2000). The measurement and dimensionality of brand associations. Journal of Product \& Brand Management, 9(6): 350-68.

Mangold, W. G., Miller, F. and Brockway, G. R. (1999). Word-of-mouth communication in the service marketplace. Journal of Services Marketing, 13(1): 73-89.

Nunnally, J. C. (1978). Psychometric theory. 2nd edn: McGraw Hill.: New York. 
Siddiqui, N., Ahmed, J. U. and Hasan, M. (2006). New generation of retail management in Bangladesh-customer satisfaction through value system management. SEU Journal of Business Studies, 2(2): 1-18.

Stafford, M. R. and Day, E. (1995). Retail services advertising: the effects of appeal, medium, and service. Journal of Advertising, 24(1): 57-71.

Swanson, S. R. and Kelley, S. W. (2001). Service recovery attributions and word-of-mouth intentions. European Journal of Marketing, 35(1/2): 194-211.

Ticehurst, G. W. and Veal, A. J. (2000). Business research methods. Longman: NSW.

Zinkhan, G. M. and Prenshaw, P. J. (1994). Good life images and brand name associations, Evidence from Asia. ACR North American Advances: America, and Europe. 